Thorax (1967), 22, 351.

\title{
Pulmonary sequestration \\ A report of an unusual case and a review of the literature
}

\author{
A R Y BLESO V S K Y 1 \\ From the Brompton Hospital, London, S.W.3
}

\begin{abstract}
A case of extralobar sequestration with findings indicating a pulmonary origin is reported. The literature has been reviewed and evidence presented that intra- and extralobar sequestration are variants of the same abnormality and that the systemic artery is an associated anomaly. From the evidence available at present the pathogenesis of this anomaly is best explained as an abnormality of bronchial and foregut budding resulting from failure of normal embryonic organizer control.
\end{abstract}

Pulmonary sequestration has become a wellrecognized clinical entity since the detailed description of intralobar sequestration by Pryce (Pryce, 1946 ; Pryce, Sellors, and Blair, 1947). The pathogenesis of, and the relationship between, intra- and extralobar sequestration remain a matter of controversy.

A case of extralobar sequestration is reported because the unusual anatomical features indicated that the lesion had a pulmonary origin.

\section{CASE REPORT}

A 42-year-old European woman presented with sudden onset of shortness of breath and pain in the left chest. On investigation she had a haemorrhagic pleural effusion (Fig. 1). No evidence of malignancy was found on microscopic examination of the effusion, at bronchoscopy or at thoracoscopy. Before the thoracoscopy the effusion was replaced by air and radiography showed a large extrapulmonary mass (Fig. 2).

At thoracotomy the findings were:

(1) A large basal pleural pocket was lined by a thick fibrous membrane.

(2) The lung had been displaced superiorly by the effusion. Projecting into the space below the level of the lung was a cyst $8 \mathrm{~cm}$. in diameter. The cyst was filled with blood clots that protruded into the pleural pocket through a $2.5 \mathrm{~cm}$. hole in the cyst (Fig. 3).

(3) The medial surface of the cyst was against the pericardium posterior to the phrenic nerve.

(4) Arising from the upper pole of the cyst was a pedicle containing two patent vessels, one a branch of the pulmonary artery arising outside the pericardium, the other a vein which entered the pericardium to join the superior pulmonary vein (Fig. 3). The cyst did not have a systemic blood supply.

1 Present address : Department of Thoracic Surgery, Shotley Bridge Hospital, nr. Consett, Co. Durham
(5) The oblique fissure of the lung was very poorly defined and shallow. There was a deep cleft in the upper lobe dividing it into two parts connected by a posterior bridge of lung (Fig. 4).

The membrane was stripped from the lung, chest wall, and diaphragm; the cyst separated with ease from the pericardium and was removed after division of the pedicle. The pedicle was dissected proximally, and the two vessels were ligated and divided at the parent vessels.

The post-operative course was uneventful. A bronchogram was performed before the patient was discharged from hospital (Fig. 5). All segments were present with the anterior segmental bronchus arising from the apical segmental bronchus.

PATHOLOGY The specimen consisted of pleura thickened by organized blood clot and an opened cyst $8 \mathrm{~cm}$. in diameter. The cyst was thin-walled except at one pole where there was an irregular thickening. Microscopically the wall of the cyst showed bronchial structures, ciliated epithelium, cartilage, and mucous glands. Muscle was scanty. There were a few areas with rudimentary bronchiolar and alveolar structures. The pedicle contained no bronchial tissue but a venous channel and an elastic pulmonary artery.

\section{DISCUSSION}

The deep cleft in the upper lobe together with a pulmonary blood supply to this example of extralobar sequestration indicated that the lesion arose in the lung and was not an accessory 'lung' but a detached segment or subsegment of the lung. The fact that the bronchogram showed no segmental bronchial deficiency does not invalidate this conclusion (Flint, 1906). Because of these findings the literature was reviewed (1) for further evidence of a pulmonary origin for extralobar sequestration ; (2) to study the relationship between intra- and 


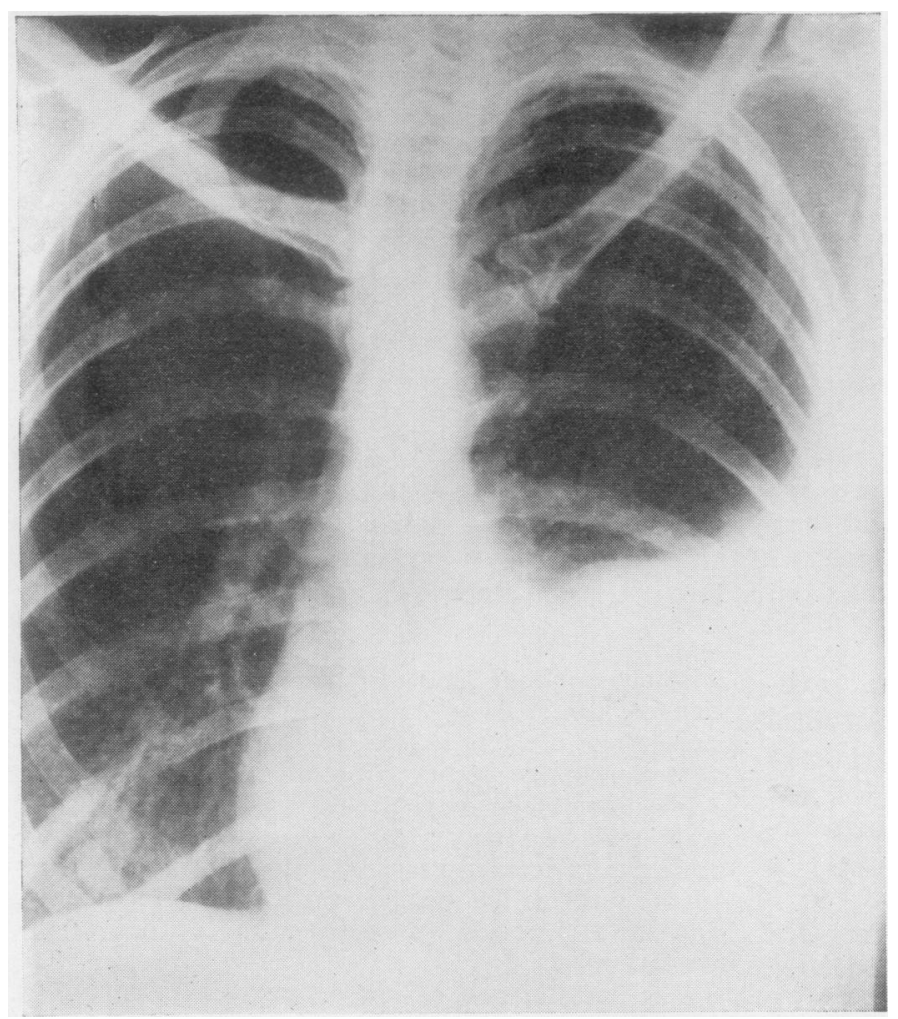

FIG. 1. Chest radiograph on admission.

FIG. 2. Chest radiograph after air replacement of pleural effusion.

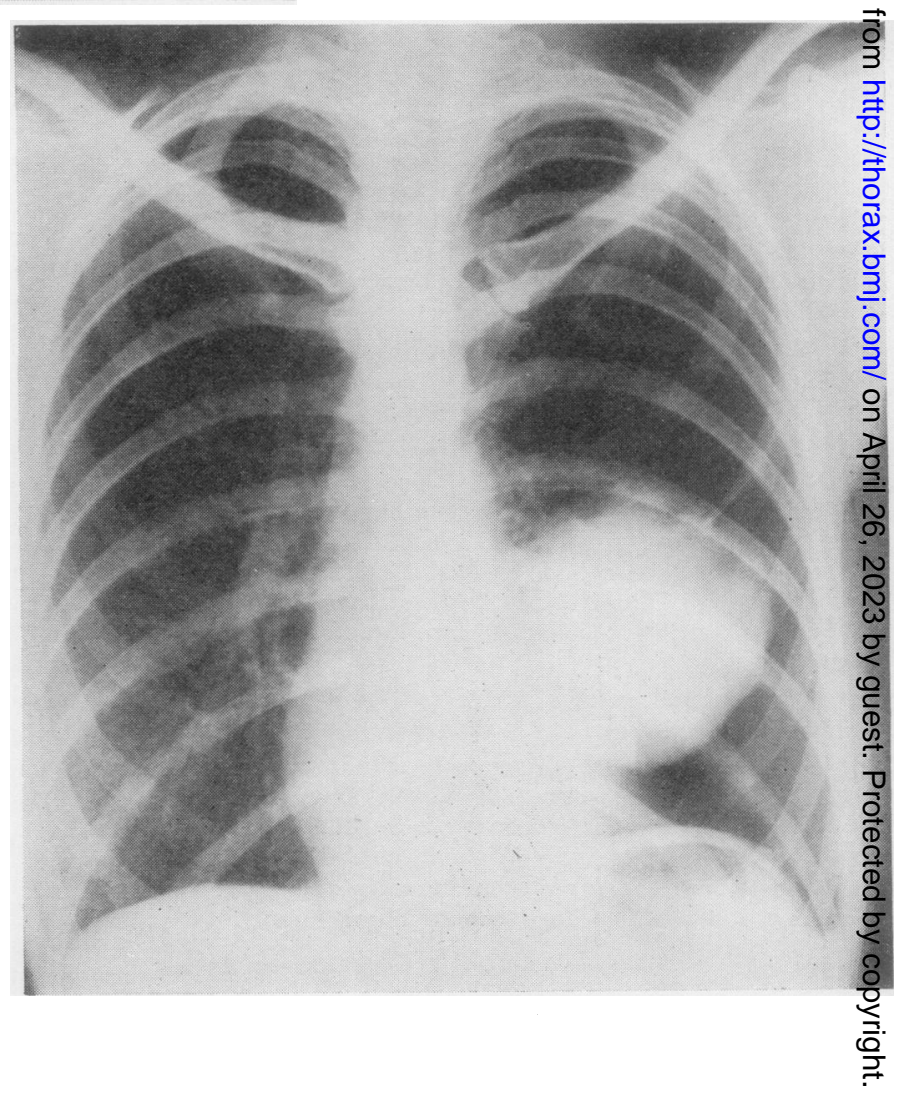




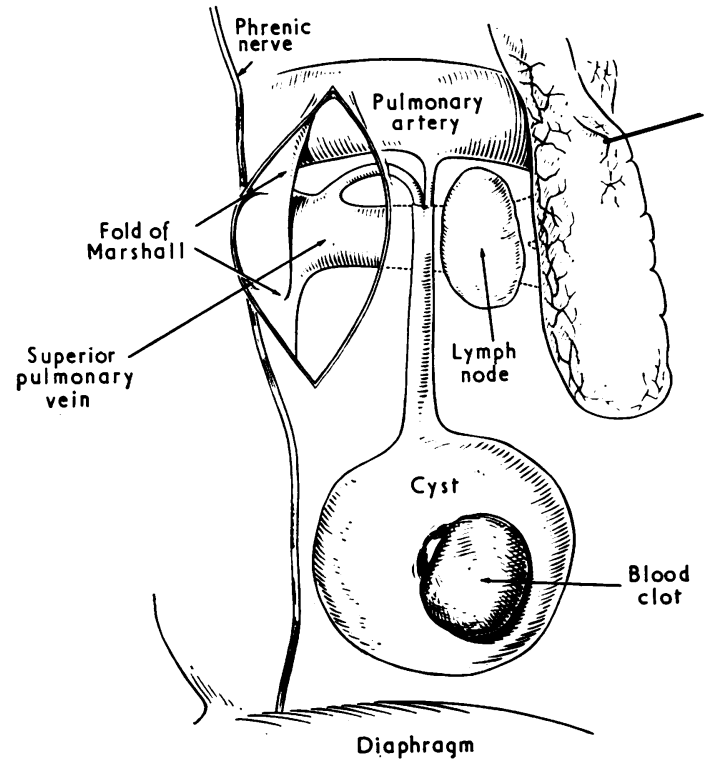

FIG. 3. Diagram of the operative findings.

extralobar sequestration ; and (3) to assess the role of the systemic arterial supply in this condition.

ORIGIN OF EXTRALOBAR SEQUESTRATION Bolck (1950), describing a case of combined intra- and extralobar sequestration, considered that seques-

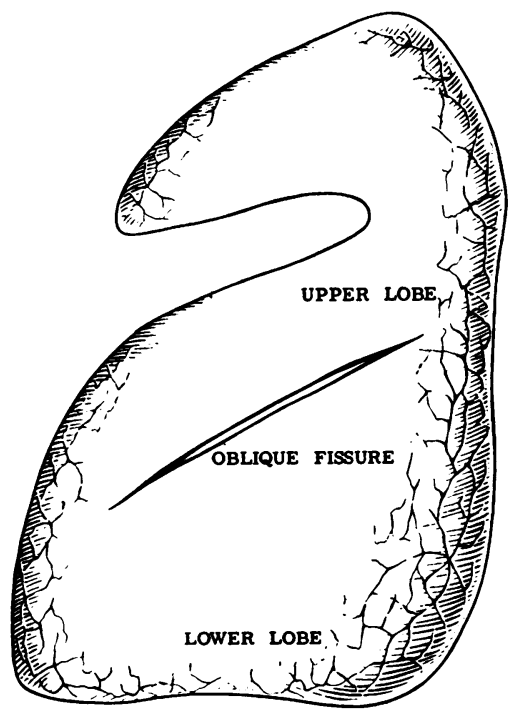

FIG. 4. Diagram of the appearance of the left lung. The oblique fissure was shallow and not more than $1 \mathrm{~cm}$. at its deepest part. trations represent a persistence of accessory bronchial buds which develop during subdivision of the primitive bronchi. These supernumerary buds are usually reabsorbed by the lung and disappear. Persistence within the lung results in intralobar sequestration ; acquisition of a blood supply when outside the lung results in persistence as an extralobar sequestration.

Abbey Smith (1956) considered intra- and extralobar sequestrations to be unrelated and precluded a pulmonary origin for the latter condition in postulating his theory of origin of the former abnormality.

A case of extralobar sequestration has been described in which the bronchus, though unconnected to the oesophagus, lay in close proximity to it (Boyden, Bill, and Creighton, 1962). Since it is known that extralobar sequestrations can be connected to the oesophagus (Gans and Potts, 1951 ; St. Raymond, Hardy, and Robbins, 1956), the authors postulated that in their case this connexion had been lost and that their example 'and other similarly located supernumerary lungs develop from a diverticulum of the oesophagus'. Similar cases arising from gastric diverticula have also been described (Scheidegger, 1936; Louw and Cywes, 1962).

It is possible that extralobar sequestration can develop from diverticula of the gut, but this theory cannot explain the findings in the present case, and a review of the literature is presented with further evidence for a pulmonary origin of extralobar sequestrations.

The finding of two cysts in an $11.7 \mathrm{~mm}$. human artery has been described (Hammar, 1904). The intralobar cyst was in the apico-posterior segment of the left upper lobe ; the extralobar cyst was in the pleural space adjacent to this segment. The shape of the second cyst suggested that it had had a connexion with the lung. The author considered that the cysts had arisen by being nipped off the developing bronchial tree.

The development of the present case is traceable from two similar cases. In the first (Warner, Britt, and Riley, 1958), the sequestration was lying within a wedge-shaped cleft in the left upper lobe ; it was entirely free of the surrounding lung and was thought to conform to the anterior segment. Its attachment was a pedicle of fibrous tissue containing its blood supply, which consisted of a branch of the pulmonary artery, a bronchial artery, and a vein running to the left innominate vein. In the second (Baar and d'Abreu, 1949), the sequestration was in the upper part of the left 


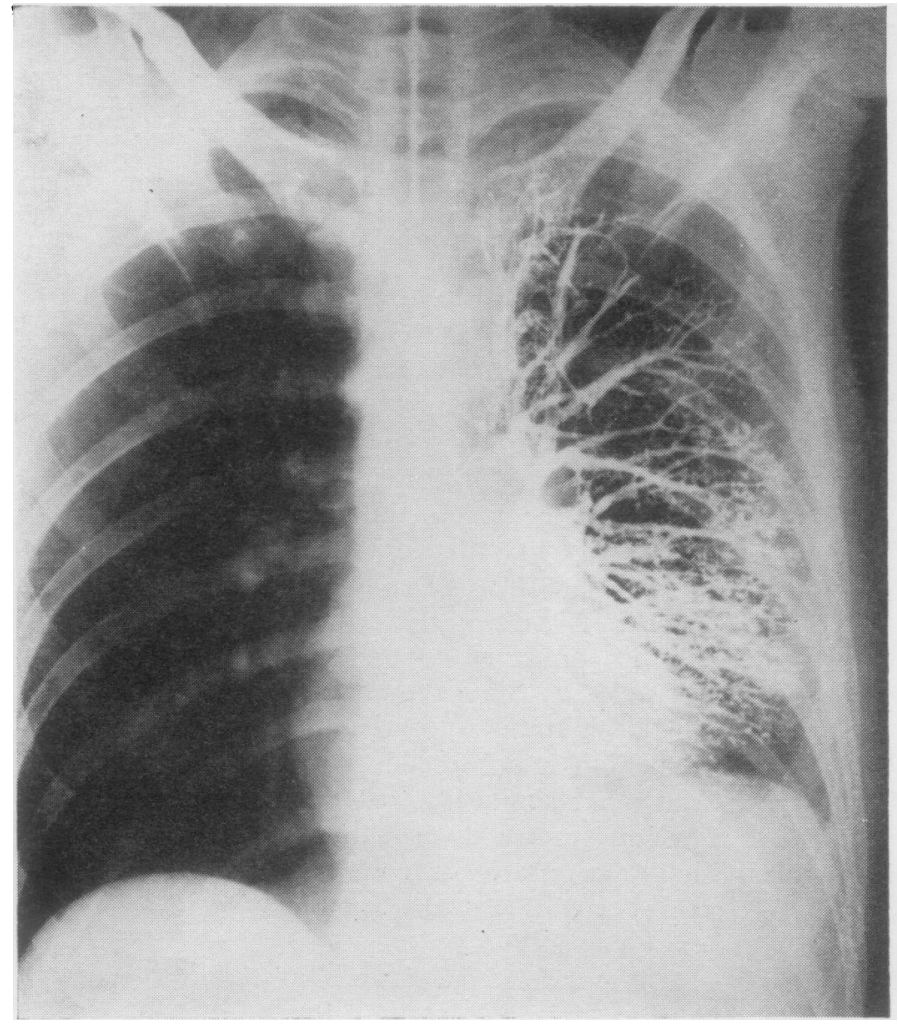

FIG. 5. Left bronchogram after operation. The anterior segmental bronchus arises high up the apical segmental bronchus and the 'gap' between the upper and lower halves of the upper lobe is seen in the lateral view.
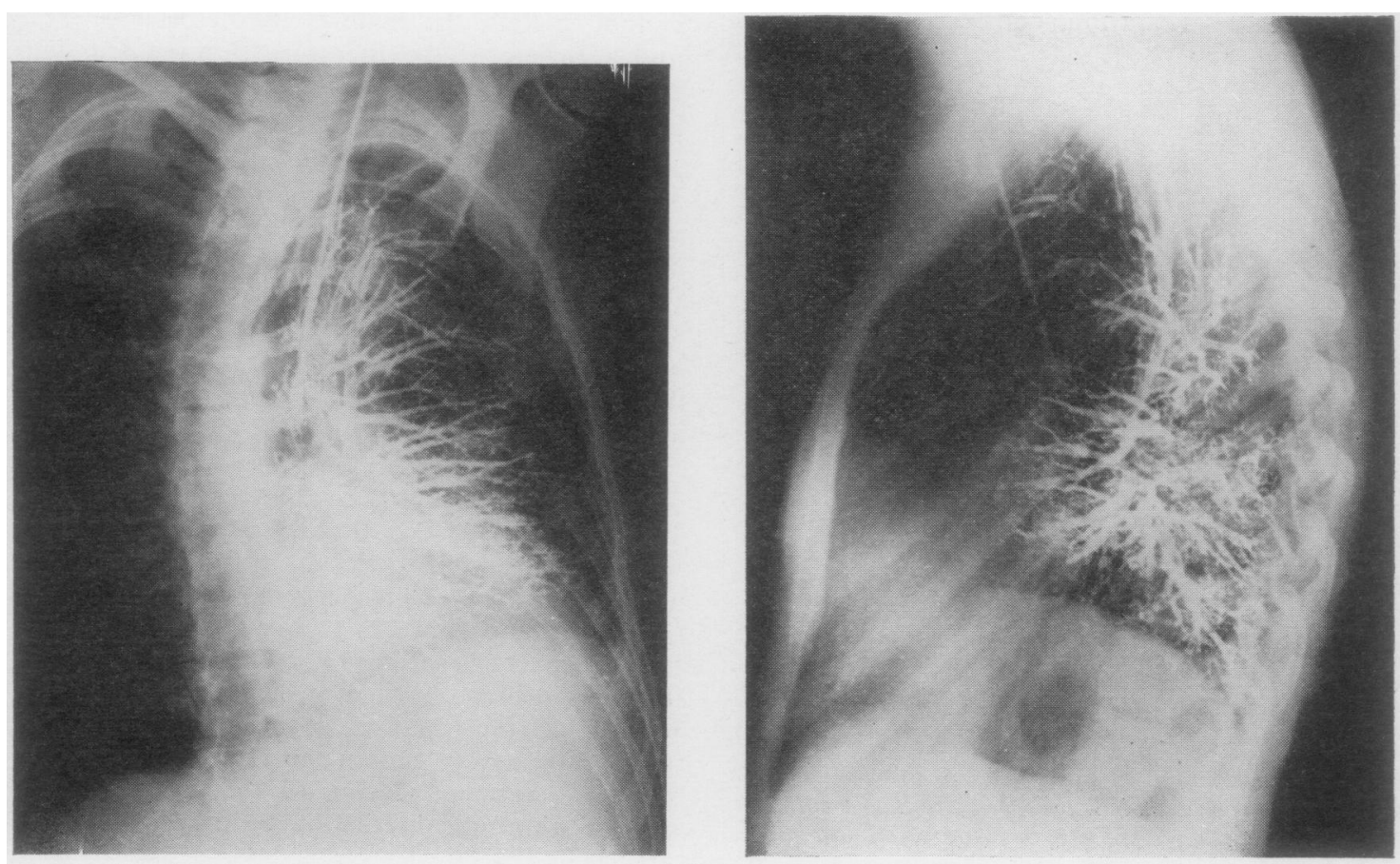


\section{T A B L E}

A. Transition from intra- to extralobar sequestration

1. Normal lung supplied by a systemic artery

McCotter, R. E., 1910

Paul (quoted by Bolck, F., 1950)

Cole et al., 1951

McLaughlin et al., 1966

2. Pulmonary sequestration with a systemic artery supplying normal lung

Pryce, D. M., 1946

Abul-Wafa, M., 1954

Bolck, F., 1950

3. Pulmonary sequestration with systemic and pulmonary artery supply

Cole et al., 1951 (Case 6)

4. Fisher (quoted by Pryce, D. M., 1946)

4. Abnormal lung without a systemic artery

5. Typical extralobar sequestration

Upper lobe

Cohn, R., and Hopeman, A., 1955

Witten et al., 1962

Lower lobe

Numerous reports since Pryce, D. M., 1946

6. Partial separation of sequestration from the lower lobe by incompletely developed tissues Weisel et al., 1955

7. Separation of sequestration from the lower lobe though still connected to it by fibrous tissue Cohn, R., and Hopeman, A., 1955 Le Roux, B. T., 1962

8. Combined intra- and extralobar sequestrations Bolck, F., 1950

Parke, W. W., 1962

Parke, W. W., 1962

Kafka, V., and Beco, V., 1960

9. Extralobar sequestration connected to a normal lobe by a pedicle

Abul-Wafa, M., 1954 (bronchus and a systemic artery)

10. Typical ow, D. (unreported case, 1965) (bronchus)

B. Pulmonary sequestration with oesophageal connexions

11. Extralobar sequestration connected to oesophagus Gans, S. L., and Potts, W. J., 1951

Boyden et al., 1962

12. Intralobar sequestration connected to oesophagus Das et al., 1959 Das et al., 1959 Beskin, C. A., 1961 13. Extralobar sequestration with connexion to oesophagus and
lung Davidson, J. S., 1956

C. Sequestration with 'uncharacteristic' features

14. Intralobar sequestration with associated anomalies See No. 12
Talalak, P., 1960

15. Intralobar sequestration with azygos drainage Weisel et al., 1955 Kergin, F. G., 1952

16. Extralobar sequestration with pulmonary blood supply Gans, S. L., and Potts, W. J., 1951

Warner et al., 1958

Baar, H. S., and d'Abreu, A., 1949 Present case

pleural space, medial to the left upper lobe outside a deep cleft in the upper lobe; the tissue was supplied by a branch of the pulmonary artery and drained by a pulmonary vein. The position in the lower chest of the present case can be explained by adhesion to the pericardium and descent with it in later development (Cockayne and Gladstone, 1917).

This orderly sequence of change is also traceable from normal lung with a systemic arterial supply to extralobar sequestrations with and without connexion to the lung (Table) and provides further evidence that some examples of this variety of sequestration originate in the lung.

RELATIONSHIP BETWEEN INTRA- AND EXTRALOBAR SEQUESTRATION There is agreement that extralobar sequestration is a congenital anomaly, whereas there is disagreement about the congenital or acquired nature of intralobar sequestration. Many authors consider the condition to be congenital and related to extralobar sequestration (Pryce, 1946 ; Kergin, 1952 ; Eaker, Hannon, and French, 1958 ; Parke, 1962).

The view that intralobar sequestration is a nonentity and the changes those of severe bronchiectasis (Gebauer and Mason, 1959) is not in keeping with the pathology (see below).

Abbey Smith (1956) has been the strongest opponent of a common origin for intra- and extralobar sequestration and has made an analysis of the differences between the two conditions. His hypothesis has been accepted by a number of authors (Gallagher, Lynch, and Christian, 1957 ; Boyden, 1958 ; Boyden et al., 1962 ; LeRoux, 1962 ; Louw and Cywes, 1962).

It is not the purpose of this article to discuss that analysis, as objections to it have been detailed (Parke, 1962), but the arguments in favour of the congenital nature of intralobar sequestration and its direct relationship to extralobar sequestration will be presented.

(1) An increasing number of cases of intralobar sequestration in young children have been reported (Cohn and Hopeman, 1955; Warner et al., 1958 ; Talalak, 1960 ; Kafka and Beco, 1960). In one child operated upon for a left lower lobe sequestration at the age of 6 years, the lesion had been demonstrated radiographically within a few hours of birth (Simopoulos, Rosenblum, Mazumdar, and Kiely, 1959).

The fact that intralobar sequestration has not been reported in neonatal post-mortem studies (Potter, 1961 ; Boyd, 1953) does not preclude its being a congenital lesion; the lesion is not a lethal one and is rarely associated with other anomalies, so its incidence in post-mortem studies will be low (extralobar sequestration was found only once in the 10,000 cases in Potter's study, and that was a gross abnormality associated with hypoplasia of the left lung); it is also a lesion particularly easy to miss unless the pulmonary ligaments are dissected for anomalous vessels and the posterior basal areas of the lung are examined.

(2) The pathology, though sometimes resembling bronchiectasis, is variable, as would be expected 
from a sequestered portion of lung not under normal growth control ; the rarity of communication with the normal bronchi (Lalli, Carlson, and Adams, 1954) is also in contrast to bronchiectasis, where the changes affect normally distributed and communicating bronchi.

(3) It is possible to trace an orderly gradation from intralobar to extralobar sequestration. These pass from a sequestration in a normally shaped lobe (the 'typical' type described in numerous reports), to a sequestration where the shape of the lobe is altered (Pryce, 1946, case II), to sequestrations with incomplete fissures (Weisel, Docksey, and Glicklich, 1955), and to those where the sequestration can be shelled away from the rest of the lobe (Cohn and Hopeman, 1955). Then there are intermediate lesions (Bolck, 1950; Parke, 1962) and combined lesions connected by narrow pedicles (Kergin, 1952; Kafka and Beco, 1960). Finally we find the lesions that lie outside a normal lobe but retain a connexion to the lobe via a bronchus (Barlow, 1965; Abul-Wafa, 1954) (Table).

A similar gradation exists in lesions connected to the oesophagus; extralobar sequestration with a bronchial pouch adjacent to but not connected with the oesophagus (Boyden et al., 1962) ; extralobar sequestration with an oesophageal diverticulum (Gans and Potts, 1951 ; St. Raymond et al., 1956); intralobar sequestration with an oesophageal diverticulum (Beskin, 1961 ; Das, Dodge, and Fawcett, 1959) ; and a stage intermediate between the last two types (Davidson, 1956) where the cyst was connected to the oesophagus and to the lung (Table).

THE ROLE OF THE SYSTEMIC BLOOD SUPPLY IN SEQUESTRATION The findings in the present case and in two others quoted above show that a systemic artery is not necessary for the development of a pulmonary sequestration, nor could traction by the vessel have played any part in the development in the present case, the findings indicating that the 'cyst' determined the course of the vessels rather than the other way about. Further arguments against the traction theory (Pryce et al., 1947) have been fully documented (Boyden, 1958).

Abbey Smith (1956) put forward the theory that the primary anomaly was a deficiency in the development of the pulmonary artery, leaving the most distal part of the lung, the posterior basal segment, unsupplied by a pulmonary artery. This part retains its primitive systemic supply, and the changes seen in the sequestration are secondary to the high pressure systemic blood supply.

Boyden, while accepting Smith's hypothesis that intra- and extralobar sequestrations are different conditions (Boyden, 1958), concluded that on the evidence then available the pulmonary and vascular lesions were associated and not causally related defects (McLaughlin, Couacoud, and Reifenstein, 1966).

In reviewing the literature, the evidence from reported cases supports the view of Boyden rather than that of Smith.

(1) Systemic vessels passing to normal lung have been reported on a number of occasions (McCotter, 1910 ; Cole, Alley, and Jones, 1951 ; McLaughlin et al., 1966).

(2) Systemic vessels associated with sequestered lung may supply normal lung (Pryce, case II, 1946 ; Abul-Wafa, 1954).

(3) Changes of sequestration are not found in cases of pulmonary artery aplasia in which the lung is supplied by bronchial vessels.

(4) In the Scimitar syndrome (Halasz, Halloran, and Liebow, 1956), anomalous drainage of the lung to the inferior vena cava is associated with bronchial and arterial anomalies. The bronchi may have cystic diverticula, and the lower lobe may have one or more systemic arteries supplying parts of the lobe deficient in pulmonary arterial supply. The bronchial diverticula when present have been in normally distributed bronchi in parts of the lung supplied by pulmonary arteries, while the lung supplied by the systemic vessels has been normal.

(5) A case has been reported in which the posterior basal segment of the left lower lobe was supplied by a systemic vessel (McLaughlin et al., ₹ 1966). The vessel was the site of severe arteritis $\frac{\text { ? }}{3}$ causing segments of total occlusion which had $D$ become revascularized by the vessel's own arterioles. The bronchi were patent. They led to $N$ aerated alveoli, and cystic changes in them were not present. The parenchyma showed areas of 0 fibrosis and chronic inflammation, with one small $\omega$ area of honeycombing. These changes were most 2 marked where the blood supply was most impaired by the arteritis in the anomalous vessel, and the $\mathbb{\mathscr { D }}$ condition of the lung was better in the areas with + a more intact blood supply. Because of the find- $\frac{T}{0}$ ing in this case the authors supported Boyden's $\stackrel{\vec{D}}{\mathbb{D}}$ view on the relationship between the pulmonary $\frac{\rho}{\mathbb{Q}}$ change in sequestration and the anomalous artery. $\stackrel{\mathbb{}}{\varrho}$

Anatomical differences have resulted in theories? differentiating not only between intra- and extra- $\rho$ 
lobar sequestration but even between extralobar sequestration situated in the upper and lower parts of the pleural cavity. From a review of the literature it is evident that this is unjustified ; just as other congenital abnormalities have a spectrum of anatomically different but related lesions (e.g., tracheo-oesophageal fistula; Fallot's tetralogy; endocardial cushion defect), pulmonary sequestration is represented by a wide variety of lesions with gradation from one end of the spectrum to the other. Though less common with intralobar sequestration, associated anomalies may be present with both types of sequestration. Sometimes the lesion is so complex that the changes cannot be explained by currently accepted theories of origin. The importance of the anomalous arterial supply has been overemphasized ; sequestration can be present without such a vessel, and normal lung can be supplied by a systemic artery.

Any theory of origin of pulmonary sequestration is unacceptable if intra- and extralobar sequestrations are treated as different conditions and if it does not explain the more complex lesions (Davidson, 1956; Talalak, 1960, case I ; Abbey Smith, 1956, unpublished case). Baar and d'Abreu (1949), in describing five abnormalities of foregut duplication (including two extralobar sequestrations and one epiphrenic diverticulum adherent to a bronchiectatic left lower lobe), explained the lesions on the basis of interference with organizer centres leading to persistence of accessory foregut buds. Cole et al. (1951) support this view and point out that a primary role cannot be ascribed to the lung, blood vessels, and diaphragm (or to the oesophagus). On the basis of this theory, interference with embryonic organization could affect all structures in an area, whether lung, blood vessels, oesophagus, pericardium, diaphragm, stomach or liver, and the relationship between the anatomically different anomalies can be explained.

I should like to thank Mr. W. P. Cleland for permission to publish the details of this case.

\section{REFERENCES}

Abul-Wafa, M. (1954). A congenital bronchopulmonary cyst associated with an anomalous artery. Thorax, 9, 167.

Baar, H. S., and d'Abreu, A. L. (1949). Duplications of the foregut Superior accessory lung ( 2 cases); epiphrenic oesophageal diverticulum; intrapericardial teratoid tumour; and oesophageal cyst. Brit. J. Surg., 37, 220.

Barlow, D. (19:5). Personal communication-unpublished case.

Beskin, C. A. (1961). Intralobar enteric sequestration of the lung containing aberrant pancreas. J. thorac. cardiovasc. Surg., 41, 314

Bolck, F. (1950). Zur Frage der Entstehung von Nebenlungen. Virchows Arch. path. Anat., 319, 20.

Boyd. G. (1953). Intralobar pulmonary sequestration. Dis. Chest, 24, 162.
Boyden, E. A. (1958). Bronchogenic cysts and the theory of intralobar sequestration: New embryologic data. J. thorac. Surg., 35, 604. Bill, A. H., Jr., and Creighton, S. A. (1962). Presumptive origin of a left lower accessory lung from an esophageal diverticulum Surgery, 52, 323.

Cockayne, E. A., and Gladstone, R. J. (1917). A case of accessory lungs associated with hernia through a congenital defect of the diaphragm. J. Anat. (Lond.), 52, 64.

Cohn, R., and Hopeman, A. (1955). Accessory pulmonary artery with intralobar sequestration of the lung. Stanf. med. Bull., 13, 361 .

Cole, F. H., Alley, F. H., and Jones, R. S. (1951). Aberrant systemic arteries to the lower lung. Surg. Gynec. Obstet., 93, 589.

Das, J. B., Dodge, O. G., and Fawcett, A. W. (1959). Intralobar sequestration of lung, associated with foregut diverticulum (oesophago-bronchial fistula) and an aberrant artery. Brit. J. Surg., 46, 582.

Davidson, J. S. (1956). A case of congenital oesophageal diverticulum, lower accessory lobe, and oesophagobronchial fistu!a. Ibid., 43 417.

Duprez, A., Wittek, F., and Dumont. A. (1956). Acquired and congenital oesophago-bronchial fistulas. Thorax, 11, 249.

Eaker, A. B., Hannon, J. L., and French, S. W. (1958). Pulmonary sequestration. Amer. J. Surg., 95, 31.

Flint, J. M. (1906). The development of the lungs. Amer. J. Anat., 6, 1

Gallagher, P. G., Lynch, J. P., and Christian, H. J. (1957). Intralobar bronchopulmonary sequestration of the lung. Report of two cases and review of the literature. New Engl. J. Med., 257, 643.

Gans, S. L., and Potts, W. J. (1951). Anomalous lobe of lung arising from the esophagus. J. thorac. Surg., 21, 313.

Gebauer, P. W., and Mason, C. B. (1959). Intralobar pulmonary sequestration associated with anomalous pulmonary vessels: nonentity. Dis. Chest, 35, 282.

Halasz, N. A., Halloran, K. H., and Liebow, A. A. (1956). Bronchial and arterial anomalies with drainage of the right lung into the inferior vena cava. Circulation, 14, 826.

Hammar, J. A. (1904). Ein Fall von Nebenlunge bei einem Menschenfotus von $11.7 \mathrm{~mm}$ Nackenlänge. Beitr. path. Anat., 36, 518.

Kafka, V., and Beco, V. (1960). Simultaneous intra- and extrapulmonary sequestration. Arch. Dis. Childh., 35, 51.

Kergin, F. G. (1952). Congenital cystic disease of lung associated with anomalous arteries. J. thorac. Surg., 23, 55

Lalli, A., Carlson, R. F., and Adams, W. E. (1954). Intralobar pulmonary sequestration. Report of 3 cases, with 2 additional cases of agenesis of right upper and middle lobes in combination with anomalous systemic vessels. Arch. Surg., 69, 797.

Le Roux, B. T. (1962). Intralobar pulmonary sequestration. Thorax, $17,77$.

Louw, J. H., and Cywes, S. (1962). Extralobar pulmonary sequestration communicating with the oesophagus and associated with a strangulated congenital diaphragmatic hernia. Brit. J. Surg., 50 , 102.

McCotter, R. E. (1910). On the occurrence of pulmonary arteries arising from the thoracic aorta. Anat. Rec., 4, 291.

McLaughlin, R. F., Jr., Couacoud, J., and Reifenstein, G. H. (1966) Bronchovascular anatomy of intralobar bronchopulmonary sequestration. Amer. Rev, resp. Dis., 93, 452

Parke, W. W. (1962). Intralobar sequestration of the lingula pulmonalis. Dis. Chest, 41, 378.

Potter, E. L. (1961). Pathology of the Fetus and Infant, 2nd ed., p. 261. Year Book Medical Publishers, Chicago.

Pryce, D. M. (1946). Lower accessory pulmonary artery with intralobar sequestration of lung: A report of seven cases. J. Path. Bact., 58, 457.

- Sellors, T. H., and Blair, L. G. (1947). Intralobar sequestration of lung associated with an abnormal pulmonary artery. Brit. J. Surg., 35, 18.

St. Raymond, A. H., Hardy, J. D., and Robbins, S. G. (1956). Lower accessory lung communicating with the esophagus and associated with congenital diaphragmatic hernia. J. thorac. Surg., 31, 354.

Scheidegger, S. (1936). Lungenmissbildungen. (Beitrag zur Entstehung der Nebenlunge.) Frankfurt Z. Path., 49, 362.

Simopoulos, A. P., Rosenblum, D. J., Mazumdar, H., and Kiely, B. (1959). Intralobar bronchopulmonary sequestration in children. J. Dis. Child. . 97, 796.

Smith, R. Abbey (1956). A theory of the origin of intralobar sequestration of lung. Thorax, 11, 10 .

Talalak, P. (1960). Pulmonary sequestration. Arch. Dis. Childh., 35, 57. Warner, C. L., Britt, R. L., and Riley, H. D. (1958). Bronchovulmonary sequestration in infancy and childhood. J. Pediat., 53, 521.

Weisel, W.. Docksey, J. W., and Glicklich, M. (1955). Vascular anomalies associated with intrapulmonary bronchial cysts. Amer. Rev. Tuberc., 71, 573.

Witten, D. M., Clagett, O. T., and Woolner, L. B. (1962). Intralobar bronchopulmonary sequestration involving the upper lobes. $J$. thorac. cardiovasc. Surg., 43, 523. 